\title{
THE SUMMER MEETING IN ITHACA
}

The fifty-second Summer Meeting of the Society was held at Cornell University, Ithaca, New York, Tuesday through Friday, August 20-23, 1946. The Mathematical Association of America met on August 19-20 and the Institute of Mathematical Statistics on August 22-23. Over five hundred people attended the meeting among whom were the following three hundred ninety-nine members of the Society:

C. R. Adams, R. B. Adams, J. G. Adshead, R. P. Agnew, A. A. Albert, P. L. Alger, E. B. Allen, C. B. Allendoerfer, Warren Ambrose, T. W. Anderson, R. C. Archibald, R. F. Arens, Silvio Aurora, M. C. Ayer, W. L. Ayers, E. G. Baker, D. H. Ballou, E. W. Barankin, J. L. Barnes, P. T. Bateman, G. E. Bates, H. P. Beard, R. L. Beinert, Stefan Bergman, D. L. Bernstein, Felix Bernstein, Lipman Bers, Garrett Birkhoff, C. J. Blackall, David Blackwell, Gertrude Blanch, E. E. Blanche, R. P. Boas, Paul Boschan, S. G. Bourne, J. W. Bower, A. H. Bowker, C. C. Bramble, R. W. Brink, A. A. Brown, B. L. Brown, H. E. Buchanan, E. F. Buck, R. C. Buck, E. L. Buell, R. S. Burington, M. L. Burke, F. J. H. Burkett, Herbert Busemann, W. H. Bussey, K. E. Butcher, S. S. Cairns, W. D. Cairns, R. H. Cameron, C. C. Camp, H. H. Campaigne, W. B. Campbell, G. F. Carrier, I. S. Carroll, K. C. Cartwright, W. B. Carver, T. E. Caywood, W. F. Cheney, Herman Chernoff, C. E. Clark, J. A. Clarkson, M. D. Clement, G. R. Clements, I. S. Cohen, L. W. Cohen, Nancy Cole, R. H. Cole, J. B. Coleman, M. A. Coler, J. A. Cooley, Byron Cosby, N. A. Court, A. P. Cowgill, W. H. H. Cowles, V. F. Cowling, M. J. Cox, H. S. M. Coxeter, H. B. Curry, J. H. Curtiss, D. R. Davis, M. M. Day, F. F. Decker, L. S. Dederick, J. L. Doob, H. L. Dorwart, C. H. Dowker, Y. N. Dowker, Arnold Dresden, W. L. Duren, Jacques Dutka, P. S. Dwyer, L. A. Dye, E. D. Eaves, Samuel Eilenberg, Benjamin Epstein, Bernard Epstein, Paul Erdös, W. S. Erickson, Luis Esteban-Carrasco, H. S. Everett, Herbert Federer, Will Feller, A. D. Fialkow, F. A. Ficken, N. J. Fine, C. D. Firestone, K. W. Folley, L. R. Ford, W. B. Ford, R. M. Foster, A. H. Fox, J. S. Frame, M. R. Freundlich, Orrin Frink, R. E. Fullerton, M. G. Gaba, C. A. Garabedian, H. L. Garabedian, H. M. Gehman, Abe Gelbart, B. H. Gere, J. J. Gergen, J. H. Giese, B. P. Gill, M. A. Girshick, J. W. Givens, A. M. Gleason, H. E. Goheen, Michael Goldberg, Samuel Goldberg, Michael Golomb, M. O. González-Rodriguez, A. W. Goodman, R. O. Goodman, M. J. Gottlieb, S. H. Gould, F. G. Gravalos, Lewis Greenwald, V. G. Grove, N. G. Gunderson, W. W. Gutzman, Theodore Hailperin, P. R. Halmos, R. W. Hamming, W. J. Harrington, B. I. Hart, C. M. Hebbert, M. H. Heins, R. G. Helsel, J. G. Herriot, Fritz Herzog, M. R. Hestenes, E. H. C. Hildebrandt, T. H. Hildebrandt, Einar Hille, M. P. Hollcroft, T. R. Hollcroft, R. H. Hoskins, Harold Hotelling, S. E. Hotelling, R. C. Huffer, H. K. Hughes, E. M. Hull, Ralph Hull, Witold Hurewicz, W. A. Hurwitz, L. C. Hutchinson, T. J. Jaramillo, R. L. Jeffery, E. D. Jenkins, S. A. Jennings, Evan Johnson, R. E. Johnson, R. F. Johnson, A. W. Jones, B. W. Jones, Harris Jones, L. G. Jones, P. S. Jones, R. C. Jones, H. A. Jordan, Mark Kac, G. K. Kalisch, Irving Kaplansky, William Karush, J. L. Kelley, A. J. Kempner, D. E. Kibbey, W. M. Kincaid, J. R. Kline, T. L. Koehler, C. F. Kossack, H. L. Krall, G. A. Larew, C. G. Latimer, V. S. Lawrence, M. A. Lee, Solomon Lefschetz, Joseph Lehner, Walter Leighton, Howard Levene, W. J. LeVeque, Norman Levinson, Harry Levy, F. A. Lewis, C. C. Lin, Charles Loewner, Z. L. 
Loflin, E. R. Lorch, Lee Lorch, A. N. Lowan, L. L. Lowenstein, C. I. Lubin, R. K. Luneburg, R. C. Lyndon, V. O. McBrien, Dorothy McCoy, N. H. McCoy, S. W. McCuskey, E. A. McDougle, A. W. McMillan, Brockway McMillan, E. J. McShane, J. K. L. MacDonald, C. C. MacDuffee, G. W. Mackey, G. R. MacLane, Saunders MacLane, M. S. Macphail, Dis Maly, Morris Marden, A. M. Mark, Ella Marth, M. H. Martin, D. C. May, A. E. Meder, L. E. Mehlenbacher, N. S. Mendelsohn, W. A. Mersman, A. N. Milgram, E. D. Miller, Norman Miller, Knox Millsaps, J. M. Mitchell, E. C. D. Molina, C. N. Moore, T. W. Moore, F. V. E. Morfoot, K. A. Morgan, Vladimir Morkovin, Richard Morris, A. P. Morse, D. S. Morse, Marston Morse, J.E. Morton, I. R. Moses, C. G. Mumford, M. E. Munroe, C. W.Munshower, W. R. Murray, J. R. Musselman, A. L. Nelson, E. D. Nering, Morris Newman, C. V. Newsom, R. E. O'Connor, E. G. Olds, L. F. Ollmann, F. W. Owens, H. B. Owens, S. T. Parker, W. V. Parker, W. H. Pell, P. M. Pepper, R. M. Peters, George Piranian, Everett Pitcher, Harry Pollard, Hillel Poritsky, William Prager, G. B. Price, A. L. Putnam, Tibor Rad6, C. H. Rawlins, C. J. Rees, Mina Rees, Irving Reiner, Eric Reissner, C. N. Reynolds, R. G. D. Richardson, E. K. Ritter, R. B. Robbins, H. P. Robertson, J. B. Robinson, R. M. Robinson, S. L. Robinson, W. J. Robinson, P. C. Rosenbloom, Arthur Rosenthal, J. B. Rosser, P. J. Rulon, Hans Samelson, Arthur Sard, F. E. Satterthwaite, S. A. Schaaf, A. C. Schaeffer, M. A. Scheier, O. F. G. Schilling, E. R. Schneckenburger, Lowell Schoenfeld, K. C. Schraut, Abraham Schwartz, G. E. Schweigert, C. H. W. Sedgewick, R. W. Sedgewick, C. E. Seely, I. E. Segal, M. E. Shanks, I. M. Sheffer, Seymour Sherman, D. M. Smiley, M. F. Smiley, C. V. L. Smith, F. C. Smith, G. W. Smith, H. W. Smith, J. C. Smith, P. A. Smith, W. M. Smith, Andrew Sobczyk, Herbert Solomon, D. E. Spencer, V. E. Spencer, E. P. Starke, N. E. Steenrod, F. F. Stephan, F. M. Stewart, E. C. Stokes, R. W. Stokes, R. R. Stoll, M. H. Stone, R. C. Strodt, W. C. Strodt, A. C. Sugar, J. L. Synge, Otto Szász, M. E. Taylor, J. M. Thomas, R. M. Thrall, W. J. Thron, Leonard Tornheim, J. I. Tracey, W. R. Transue, W. J. Trjitzinsky, C. A. Truesdell, Y. W. Tschen, A. W. Tucker, J. W. Tukey, A. R. Turquette, F. E. Ulrich, H. E. Vansant, Abraham Wald, G. L. Walker, G. W. Walker, R. J. Walker, S. E. Walkley, Henry Wallman, J. L. Walsh, J. B. Walton, C. W. Watkeys, J. V. Wehausen, Alexander Weinstein, F. P. Welch, C. P. Wells, E. T. Welmers, G. W. Whitehead, E. A. Whitman, P. M. Whitman, W. F. Whitmore, Hassler Whitney, G. T. Whyburn, D. V. Widder, V. A. Widder, A. S. Wightman, J. E. Wilkins, S. S. Wilks, G. M. Wing, František Wolf, H. A. Wood, P. M. Young, J. W. T. Youngs, Oscar Zariski, J. A. Zilber, Antoni Zygmund.

On Tuesday afternoon, Wednesday, Thursday and Friday mornings, Professor Hassler Whitney of Harvard University gave the Colloquium Lectures on Topology of smooth manifolds. President T. H. Hildebrandt and Vice Presidents J. M. Thomas, L. R. Ford and Saunders MacLane presided in turn at these lectures.

Professor M. H. Stone of the University of Chicago on Wednesday morning gave his retiring presidential address entitled Some general principles of functional representation. President Hildebrandt presided.

On Thursday afternoon Professor J. L. Doob of the University of Illinois gave an address on Probability in function space. Professor S. S. Wilks presided. 
Presiding officers for the sessions of contributed papers were: Topology, Tuesday afternoon, Professor G. T. Whyburn; Applied Mathematics, Tuesday afternoon, Dr. Hillel Poritsky; Statistics and Probability, Thursday morning, President W. G. Cochran of the Institute of Mathematical Statistics; Algebra and Theory of Numbers, Thursday morning, Professor Samuel Eilenberg; Analysis, Thursday afternoon, Professor M. R. Hestenes; Geometry, Thursday afternoon, Professor Oscar Zariski; Analysis, Friday morning, Professor G. B. Price; Algebra and Topology, Friday morning, Professor S. S. Cairns.

There was a business meeting Wednesday morning at which President T. H. Hildebrandt presided.

The general sessions were all held in 200 Baker Laboratory and the sections in this room and in 7 Baker Laboratory.

Registration headquarters were in Risley Hall. Balch and Risley dormitories were available to those attending the meetings. Meals were served in Willard Straight Hall and Martha Van Rennselaer Hall.

The ladies of the Cornell University Department of Mathematics served tea on Monday and Thursday afternoons.

On Tuesday afternoon the members of the mathematical organizations, their families and guests, were entertained at tea at the home of Professor Emeritus W. B. Ford of the University of Michigan and Mrs. Ford. The Fords have a beautiful home on the west shore of Cayuga Lake about twenty-five miles north of Ithaca. Tea was served on the porches and lawn overlooking the lake. Both the setting and the weather were ideal.

On Tuesday evening the Walden String Quartette entertained the mathematicians and their friends with a delightful program.

A group photograph was taken at 1:30 P.M., Wednesday.

For the Wednesday afternoon outing, a choice was given of either dining at The Krebs or going on a picnic. The Krebs is a famous restaurant at Skaneateles, New York. The picnic was held in Robert H. Treman State Park, Upper Enfield Glen.

The dinner for the three organizations was served in the Ivy Room and adjacent rooms of Willard Straight Hall. After dinner, the group adjourned to Memorial Hall for the program of the evening. The toastmaster, Professor C. B. Allendoerfer, introduced Provost Adams of Cornell University who gave an address of welcome, following which brief addresses were given by Professors P. A. Smith, L. R. Ford and Harold Hotelling. Professor C. C. Camp proposed a resolution, unanimously approved, expressing the appreciation of the members of the three organizations to the President and administration of Cornell 
University, Professor and Mrs. W. B. Ford, the local committee and all who assisted them for their excellent arrangements and cordial hospitality.

The Council met at 8:15 P.M. on August 20,1946, and at 2:15 P.M. on August 21, 1946, in Willard Straight Hall.

The Secretary announced the election of the following forty persons to membership in the Society:

Mr. Richard Davis Anderson, University of Texas;

Mr. Howard Clinton Arnold, Federal Enamel and Stamping Co., Pittsburgh, Pa.;

Mr. Albert Abraham Blank, Brown University;

Professor James Lawrence Botsford, Reed College;

Mrs. Joan Robinson Clark, Brown Instrument Co., Philadelphia, Pa.;

Mr. Francis Eugene Cothran, Los Angeles, Calif.;

Mr. William John Culmer, Radio Corporation of America, Indianapolis, Ind.;

Mr. William Carl Davis, Stockham Pipe Fittings Co., Birmingham, Ala.;

Mrs. Georgia Knox Del Franco, University of Miami;

Professor Flora Dinkines, University of South Carolina;

Professor Luis Esteban-Carrasco, University of Madrid;

Miss Charlotte Gladys Dragstedt, University of Chicago;

Mr. Bertram Morris Drucker, University of North Carolina;

Mr. Joseph H. Engel, New York, N. Y.;

Mrs. Norma MacLeod Gilbert, New York, N. Y.;

Mr. Oscar Goldman, Palmer Physical Laboratory, Princeton University;

Professor Edison Greer, Kansas State College;

Mr. Cornelius Groenewoud, Lieutenant, U.S.A.;

Mr. Norman Tyson Hamilton, Princeton University;

Mr. Alan Jerome Hoffman, New York, N. Y.;

Mr. Chuan Chih Hsiung, Michigan State College;

Mr. Ralph Bernard Johnson, University of Tennessee;

Mr. Rufus Alexander Koerting, University of Wisconsin;

Mr. Benjamin Lepson, Columbia University;

Mr. Edgar Linton, Kansas City, Mo.;

Professor Joe James Livers, Montana State College, Bozeman, Mont.;

Mrs. Chin Hua Liu Lu, Boston, Mass.;

Mr. Gregory Joseph Mann, Wright Junior College;

Mr. Bernard Mason, New York, N. Y.;

Dr. Eric M. Michalup, Caracas, Venezuela;

Professor Raymond David Mindlin, Department of Civil Engineering, Columbia University;

Miss Gabrielle Marcelle Morin, Columbia University;

Professor Rosa Catherine Paschal, Anderson College, Anderson, S. C.;

Dr. Roy Bly Saunders, University of Minnesota;

Mr. I. Richard Savage, Detroit, Mich.;

Dr. Henry Maksymiljan Schaerf, Montana State College;

Mr. William Raymond Scott, Ohio State University;

Mr. Robert Rex Seeber, Jr., Watson Scientific Computing Laboratory, New York, N. Y.;

Professor Kenichi Watanabe, University of Hawaii;

Mr. Albert Wilansky, Brown University. 
The following appointments by President T. H. Hildebrandt were reported: Professors B. W. Jones (Chairman), T. R. Hollcroft, W. T. Martin, J. B. Rosser, and R. J. Walker as a Committee on Arrangements for the 1946 Summer Meeting at Cornell University; Professors Arnold Dresden (Chairman), H. W. Brinkmann, J. A. Clarkson, T. R. Hollcroft, B. W. Jones, C. O. Oakley, and J. C. Oxtoby as a Committee on Arrangements for the 1946 Annual Meeting at Swarthmore College; Professors A. W. Tucker (Chairman), R. H. Fox, T. R. Hollcroft, and Marston Morse as a Committee on Arrangements for the fall eastern meeting at Princeton University on November 2, 1946; Professor O. E. Neugebauer as the representative of the Society at a possible conference for discussion of an abstract journal in applied mechanics; Professor A. W. Tucker as a member of the Committee on Aid to Devastated Libraries (to replace Professor Solomon Lefschetz); Professor J. L. Synge as the representative of the Society on the Committee on American Participation for the Sixth International Congress for Applied Mechanics, to be held in Paris on September 22-29, 1946.

The appointment by the President of Professor Philip Franklin as the representative of the Society on the Council of the American Association for the Advancement of Science for the year 1946 was confirmed.

Times and places of meetings during 1947 were set as follows: February 22, April 25-26 and October 25 in New York City; April 25-26 in Chicago; April 26 at Stanford University.

It was reported that Professor D. C. Spencer had been invited to deliver an address at the November, 1946, meeting in Los Angeles, California, and that Professor S. E. Warschawski had been invited to deliver an address at the November, 1946, meeting in Ames, Iowa.

On recommendation of the Committee on Places of Meetings, the Council voted to hold the 1947 Summer Meeting at Yale University and the 1947 Annual Meeting at the University of Georgia.

On the recommendation of the Colloquium Editorial Committee, the Council voted to invite Professor T. Y. Thomas to deliver a series of Colloquium Lectures in 1948.

The resignation of Associate Secretary W. L. Ayres was accepted with regret. On recommendation of the Committee on Nominations, the Council elected Professor G. B. Price to fill the unexpired term of Professor Ayres, this term to expire December 31, 1947. (This election was later confirmed by the Board of Trustees.)

Professors Solomon Lefschetz and G. T. Whyburn were appointed representatives of the Society on the Council of the American Asso- 
ciation for the Advancement of Science for the year 1947.

Professors R. V. Churchill and M. R. Hestenes were nominated as representatives of the Society in the Division of Physical Sciences of the National Research Council for the three-year period beginning July 1, 1947.

The committee which had been studying problems connected with the publication of the complete works of the late Professor G. D. Birkhoff reported to the Council. The committee was requested to re-study certain aspects of the question in the light of Council discussion.

The Council voted to invite Professor P. M. Morse of Massachusetts Institute of Technology to deliver the twenty-first Josiah Willard Gibbs Lecture at the 1947 Annual Meeting.

The Council voted to invite Professor Heinz Hopf of the Federal Institute of Technology in Zurich, Switzerland, as Visiting Lecturer for the academic year 1946-1947. (Professor Hopf found it impossible to accept this invitation.)

Professor M. H. Stone reported for the Policy Committee for Mathematics that the committee had discussed in detail a number of problems which face the mathematical profession in the post-war period. Prominent among these are: the various science bills before Congress; atomic research, particularly as it affects freedom of scientific investigation; the various changes in Selective Service regulations; international cooperation problems raised by the United Nations Educational, Scientific and Cultural Organization. A report of the activities of this committee for the period October 1, 1945-June 30, 1946, was submitted during the summer of 1946 to the Rockefeller Foundation, which has been supporting the work of the committee.

Professor Arnold Dresden reported for the Committee on Aid to Devastated Libraries that a request for members of the Society to contribute books, journals and cash to aid such libraries was to be inserted in a forthcoming issue of the Bulletin. The Council voted, on recommendation of this committee, to make certain recommendations to the Board of Trustees in connection with contributions of the Society to this project, to discharge the committee, and to appoint a committee of three to work out the proper distribution of the material collected in response to the Bulletin notice.

The Secretary was authorized to arrange a reciprocity agreement with the Société Mathématique de France similar to agreements with other societies abroad.

The Council authorized the President to appoint a committee to consult with the editors of the Annals of Mathematics regarding the 
publication problems of that journal.

The President was authorized by the Council to appoint a committee to consider the relation of the Society to the various groups of applied mathematicians.

The question of the United Nations Educational, Scientific and Cultural Organization, as it relates to international mathematical organization, was referred to the Policy Committee for Mathematics for discussion.

Titles and cross references to the abstracts of papers read are given below: papers $1-4$ in the section for Topology, Tuesday afternoon; papers 5-9 in the section for Applied Mathematics, Tuesday afternoon; papers 10-16 in the section for Statistics and Probability, Thursday morning; papers 17-23 in the section for Algebra and Theory of Numbers, Thursday morning; papers 24-31 in the section for Analysis, Thursday afternoon; papers 32-39 in the section for Geometry, Thursday afternoon; papers $40-48$ in the section for Analysis, Friday morning; papers 49-57 in the section for Algebra and Topology, Friday morning; papers 58-111, whose abstract numbers are followed by the letter $t$, were read by title. Paper 1 was read by Professor Kelley, paper 28 by Professor Hughes, paper 32 by Professor V. G. Grove for the author, paper 51 by Professor Birkhoff, paper 54 by Dr. Poritsky, paper 57 by Professor Eilenberg. Sister Petronia was introduced by Professor Karl Menger and Professor Ancochea was introduced by Professor Oscar Zariski.

1. R. F. Arens and J. L. Kelley: Characterization of the space of continuous functions. (Abstract 52-7-258.)

2. Herbert Federer: Dimension and measure. (Abstract 52-9-340.)

3. J. W. T. Youngs: The representation problem for Fréchet surfaces. Preliminary report. (Abstract 52-9-346.)

4. Felix Bernstein: A new four-color problem. (Abstract 52-7-259.)

5. A. C. Sugar: On the relaxation-matrix method of solving boundary value problems. (Abstract 52-7-248.)

6. Alexander Weinstein: On the method of sources and sinks. (Abstract 52-9-317.)

7. William Prager: On the variational principles of plasticity. (Abstract 52-9-313.)

8. C. A. Truesdell: On Behrbohm and Pinl's linearization of the equation of two-dimensional steady flow of a compressible adiabatic fluid. (Abstract 52-9-316.)

9. S. A. Schaaf: On the superposition of a heat source and a contact resistance. (Abstract 52-7-246.) 
10. Howard Levene: $A$ test of randomness in two dimensions. (Abstract 52-7-257.)

11. Herman Rubin: Asymptotic distribution of moments from a system of linear stochastic difference equations. (Abstract 52-9-332.)

12. David Blackwell: Conditional expectation and unbiased sequeniial estimation. (Abstract 52-9-327.)

13. Mark Kac: $A$ discussion of the Ehrenfest model. Preliminary report. (Abstract 52-7-256.)

14. J. W. Tukey: Sampling from contaminated distributions. Preliminary report. (Abstract 52-9-334.)

15. Leo Katz: On the class of functions defined by the difference equation $(x+1) f(x+1)=(a+b x) f(x)$. (Abstract 52-9-330.)

16. F. E. Satterthwaite: Retention of decimal places in matrix calculations. (Abstract 52-9-333.)

17. R. C. Buck: The measure-theoretic approach to density. (Abstract 52-9-266.)

18. J. S. Frame: On the reduction of the conjugating representation of a finite group. (Abstract 52-9-268.)

19. Orrin Frink: Complemented modular lattices and projective spaces of infinite dimension. (Abstract 52-7-225.)

20. H. S. M. Coxeter: Integral Cayley numbers. (Abstract 52-7-223.)

21. C. N. Moore: On the infinitude of prime pairs. (Abstract 52-9271.)

22. R. M. Robinson: Primitive recursive functions. (Abstract 52-9274.)

23. P. T. Bateman: On the representations of a number as the sum of three squares. (Abstract 52-9-262.)

24. G. R. MacLane: Concerning the uniformization of certain Riemann surfaces allied to the inverse-cosine and inverse-gamma surfaces. (Abstract 52-7-236.)

25. J. G. Herriot: On the restricted summability of multiple Fourier series. Preliminary report. (Abstract 52-9-296.)

26. Y. W. Tschen: Branch points and flat points of minimal surfaces in $R^{3}$. (Abstract 52-9-310.)

27. J. A. Clarkson: A characterization of $C$-spaces. (Abstract 52-9288.)

28. H. K. Hughes and Cleota G. Fry: Asymptotic developments of types of generalized Bessel functions. (Abstract 52-9-297.)

29. A. W. Goodman: On some determinants related to p-valent functions. Preliminary report. (Abstract 52-9-292.)

30. S. H. Gould: Lagrange multipliers and functional determinants. (Abstract 52-9-293.) 
31. Stefan Bergman: The "extended class" in the theory of functions of two complex variables. (Abstract 52-9-285.)

32. C. C. Hsiung: Projective theory of surfaces and conjugate nets in four-dimensional space. (Abstract 52-9-321.)

33. N. A. Court: On the biratio of the altitudes of a tetrahedron. (Abstract 52-7-252.)

34. V. G. Grove: On congruences and conjugate nets. (Abstract 52-9320.)

35. Herbert Busemann: Intrinsic area. (Abstract 52-7-251.)

36. Tibor Radó: The isoperimetric inequality and the Lebesgue definition of surface area. I. (Abstract 52-7-253.)

37. L. A. Dye: $A$ Cremona transformation in $S_{3}$ defined by a pencil of quartic surfaces. (Abstract 52-9-318.)

38. Michael Goldberg: Tubular linkages. (Abstract 52-9-319.)

39. G. W. Walker: Games of the checkers family in line, plane, and space. (Abstract 52-9-325.)

40. Bernard Epstein: Integral representations of solutions of certain classes of partial differential equations. (Abstract 52-9-290.)

41. William Karush: $A$ semi-strong minimum for a double integral problem in the calculus of variations. (Abstract 52-7-234.)

42. Josephine M. Mitchell: Value distribution of a function of two complex variables in a domain with distinguished boundary surface. (Abstract 52-9-302.)

43. J. L. Synge: Approximations in elasticity based on the concept of function space. (Abstract 52-9-315.)

44. I. M. Sheffer: On k-periodic systems of linear equations. (Abstract 52-9-307.)

45. Otto Szász: On the Möbius inversion formula and closed sets of functions. (Abstract 52-7-240.)

46. R. P. Agnew: Methods of summability which evaluate sequences of zeros and ones summable $C_{1}$. (Abstract 52-9-281.)

47. George Piranian: Infinite iteration of totally regular transformations. Preliminary report. (Abstract 52-9-303.)

48. František Wolf: On the continuation of analytic functions. (Abstract 52-9-311.)

49. Irving Kaplansky: Topological rings. (Abstract 52-7-226.)

50. G. K. Kalisch: Uniform spaces and topological groups as generalized metric spaces. (Abstract 52-5-121.)

51. Garrett Birkhoff and P. M. Whitman: Representation theory for certain non-associative algebras. (Abstract 52-9-263.)

52. S. A. Jennings: The group ring of a class of infinite nilpotent groups. (Abstract 52-9-269.) 
53. Irma $R$. Moses: On the representation, in the ring of p-adic integers, of a quadratic form in $n$ variables by one in $m$ variables. (Abstract 52-9-272.)

54. Hillel Poritsky and D. W. Dudley: Conjugate action of involute helical gears with inclined axes. (Abstract 52-9-312.)

55. Witold Hurewicz: Algebraic and topological classification of mappings. (Abstract 52-9-341.)

56. N. J. Fine: On the Walsh functions. Preliminary report. (Abstract 52-9-291.)

57. Samuel Eilenberg and Saunders MacLane: Determination of the second homology and cohomology groups of a space by means of homotopy invariants. (Abstract 52-11-399.)

58. R. P. Agnew: Subseries of series which are not absolutely convergent. (Abstract 52-9-282-t.)

59. Germán Ancochea: Zariski's proof of the theorem of BertiniEnriques in the case of an arbitrary ground field. (Abstract 52-11387-t.)

60. R. F. Arens: Convex topological algebras. Preliminary report. (Abstract 52-9-336-t.)

61. R. F. Arens: Duality in topological linear spaces. (Abstract 529-337-t.)

62. H. P. Atkins: On fractional derivatives of univalent functions. (Abstract 52-9-283-t.)

63. J. D. Bankier: Modified regular continued fractions. Preliminary report. (Abstract 52-9-284-t.)

64. H. W. Becker: Stirling's numbers of the third kind. (Abstract 52-9-326-t.)

65. Stefan Bergman: On functions which satisfy certain systems of partial differential equations. (Abstract 52-7-229-t.)

66. R. H. Bing: Skew sets. (Abstract 52-9-338-t.)

67. G. D. Birkhoff and D. C. Lewis: Chromatic polynomials. (Abstract 52-9-339-t.)

68. Paul Boschan: The consolidated Doolittle technique. (Abstract 52-9-328-t.)

69. A. T. Brauer: Limits for the characteristic roots of a matrix. (Abstract 52-9-264-t.)

70. Ellen F. Buck and R. C. Buck: $A$ note on finitely-additive measures. (Abstract 52-9-265-t.)

71. C. C. Camp: Integral equations with kernels having discontinuities along two diagonals. (Abstract 52-9-287-t.)

72. H. S. M. Coxeter: $A$ simple proof of the eight square theorem. (Abstract 52-7-222-t.) 
73. H. V. Craig: On the structure of intrinsic derivatives. (Abstract 52-9-289-t.)

74. Roy Dubisch: On the direct product of rational generalized quaternion algebras. (Abstract 52-7-224-t.)

75. R. J. Duffin: Nonlinear networks. III. (Abstract 52-7-243-t.)

76. W. F. Eberlein: Weak sequential compactness and regularity of Banach spaces. (Abstract 52-7-231-t.)

77. C. J. Everett and H. J. Ryser: Rational vector spaces. (Abstract 52-9-267-t.)

78. Evelyn Frank: The real parts of the zeros of a complex polynomial. (Abstract 52-7-232-t.)

79. W. H. Gottschalk and G. A. Hedlund: Recursive properties of transformation groups. (Abstract 52-7-260-t.)

80. M. H. Heins: On the Phragmen-Lindelöf principle. (Abstract 52-9-295-t.)

81. P. G. Hoel: The efficiency of the mean moving range. (Abstract 52-9-329-t.)

82. B. F. Kimball: Some basic theorems for developing tests of fit for the case of the non-parametric probability distribution function. (Abstract 52-9-331-t.)

83. D. C. Lewis: On polynomial interpolation and extrapolation by least squares with arbitrary weight function. (Abstract 52-9-298-t.)

84. Szolem Mandelbrojt and G. R. MacLane: On functions holomorphic in a strip region and an extension of Watson's problem. (Abstract 52-9-299-t.)

85. P. R. Masani: Laurent factorization of analytic functions in normed rings. (Abstract 52-9-300-t.)

86. P. R. Masani: Multiplicative Riemann integration in normed rings. (Abstract 52-9-301-t.)

87. B. E. Meserve: Inequalities of higher degree. (Abstract 52-9270-t.)

88. Harry Pollard: The inversion of the transforms with reiterated Stieltjes kernels. (Abstract 52-9-304-t.)

89. Harry Pollard: The representation of $e^{-x \lambda}$ as a Laplace integral. (Abstract 52-9-305-t.)

90. M. H. Protter: Generalized spherical harmonics. (Abstract 527-238-t.)

91. Tibor Radó: The isoperimetric inequality and the Lebesgue definition of surface area. II. (Abstract 52-7-254-t.)

92. W. T. Reid: Solutions of linear differential equations. (Abstract 52-9-306-t.) 
93. C. E. Rickart: The singular elements of a Banach algebra. (Abstract 52-9-273-t.)

94. H. E. Salzer: Alternative formulas for direct interpolation of a complex function tabulated along equidistant circular arcs. (Abstract 52-7-245-t.)

95. R. D. Schafer: Concerning automorphisms of non-associative algebras. (Abstract 52-9-275-t.)

96. A. R. Schweitzer: Sums and products of ordered dyads in the foundations of algebra. III. (Abstract 52-9-276-t.)

97. A. R. Schweitzer: Sums and products of ordered dyads in the foundations of algebra. IV. (Abstract 52-9-277--t.)

98. I. E. Segal: Irreducible representations of operator algebras. (Abstract 52-7-239-t.)

99. Seymour Sherman: Stability calculations and time lag. (Abstract 52-5-179-t.)

100. S. S. Shü: On Taylor and Maccoll's equation of a cone moving in the air with supersonic speed. (Abstract 52-9-314-t.)

101. Abraham Spitzbart: The minimum of a certain integral. (Abstract 52-9-308-t.)

102. A. C. Sugar: An elementary exposition of the relaxation method. (Abstract 52-7-247-t.)

103. Fred Supnick: $A$ theorem on rectilinear deformation. (Abstract 52-9-342-t.)

104. Fred Supnick: On the packing of spheres. I. (Abstract 52-9323-t.)

105. Fred Supnick: Topology of sphere clusters. I. (Abstract 52-9343-t.)

106. Fred Supnick: Topology of sphere clusters. II. Analogue of Kuratowski's theorem. (Abstract 52-9-344-t.)

107. W. J. Trjitzinsky: Singular integral equations of the first kind and those related to permutability and iteration. (Abstract 52-9-309-t.)

108. Sister Petronia Van Straten: Toroidal and non-toroidal graphs. (Abstract 52-9-345-t.)

109. M. L. Vest: An involutorial space transformation associated with a $Q_{1, n}$ congruence. (Abstract 52-9-324-t.)

110. Jacob Wolfowitz: Confidence limits for the fraction of a normal population which lies between two given limits. (Abstract 52-9-335-t.)

111. Oscar Zariski: The concept of a simple point of an abstract algebraic variety. (Abstract 52-11-393-t.)

T. R. Hollcroft, Associate Secretary 